\section{Environmental Variance and Broad-sense Heritability of Nut Traits in Japanese Chestnut Breeding}

\author{
Sogo Nishio², Masahiko Yamada, Norio Takada, Hidenori Kato, \\ Noriyuki Onoue ${ }^{1}$, Yutaka Sawamura, and Toshihiro Saito \\ NARO Institute of Fruit Science, 2-1 Fujimoto, Tsukuba, Ibaraki 305-8605, \\ Japan
}

Additional index words. Castanea crenata, genetic variance, genetic variation, phenotypic selection

\begin{abstract}
We evaluated the nut harvesting date (NHD), nut weight (NW), pericarp splitting (PS), and infestation by insects (II) in eight cultivars/selections of Japanese chestnut, including a Japanese-Chinese hybrid, over 6 years. Data were analyzed by analysis of variance (without transformation for NHD, after log-transformation for NW and PS, and after square root transformation for II). The among-tree variance accounted for only $1.1 \%$ to $8.5 \%$ of the total variance. The variance component resulting from residual factors for the tree $\times$ year interaction and sampling errors was the largest component for NW, PS, and II, accounting for $46 \%$ to $54 \%$ of the total environmental variance. Because tree replication is costly and time-consuming in chestnut breeding, increasing the number of yearly repetitions is more efficient than increasing the number of tree replicates. Broad-sense heritability was 0.84 for $\mathrm{NHD}, 0.27$ for $\mathrm{NW}, 0.48$ for PS, and 0.17 for $\mathrm{II}$ in evaluations with one tree without yearly repetition. It increased to 0.91 for NHD, 0.40 for NW, 0.62 for PS, and 0.29 for II in evaluations with one tree in 2 years. For NHD, the heritabilities are sufficiently high to distinguish genetic differences among cultivars/selection. In contrast, the low heritability of II suggests that this trait should not be evaluated with an emphasis on the initial selection stage but rather with an emphasis on the secondary selection stage based on testing at several locations with a large number of yearly and tree replications.
\end{abstract}

The chestnut (Castanea spp.) has been an important food source in East Asia, Asia Minor, Europe, and North America for centuries. Three main chestnut species are currently produced commercially and are naturally distributed around the world: Japanese chestnut (C. crenata Sieb. et Zucc.) in Japan and the Korean Peninsula, Chinese chestnut (C. mollissima Bl.) in China, and European chestnut (C. sativa Mill.) in Europe and Asia Minor.

The history of chestnut use in Japan is very long. For example, a large number of chestnut pericarps and large chestnut timbers were found in a tower at the Sannai-Maruyama ruins (3500 to $2000 \mathrm{BCE}$ ) in Aomori Prefecture, northern Japan (Sawamura, 2006). For primitive Japanese people, chestnuts were important sources of food and construction materials. Even now, they are commercially grown throughout Japan for food, and chestnut orchards covered more than 21,400

Received for publication 20 Feb. 2014. Accepted for publication 27 Mar. 2014.

This research owes a debt to the many persons involved in Japanese chestnut breeding at the NARO Institute of Fruit Tree Science. We are sincerely grateful for their efforts.

${ }^{1}$ Present address: Grape and Persimmon Research Station, NARO Institute of Fruit Tree Science, Akitsu, Higashihiroshima 739-2494, Japan.

${ }^{2}$ To whom reprint requests should be addressed; e-mail nishios@affrc.go.jp. ha in 2011, ranking fourth among woody fruit and nut crops in Japan after citrus, apple, and persimmon (FAOSTAT, 2013).

An organized chestnut breeding program started in 1947 at the National Institute of Fruit Tree Science in Japan and continues at the National Agriculture and Food Research Organization (NARO) Institute of Fruit Tree Science (NIFTS; Kotobuki et al., 1999; PereiraLorenzo et al., 2012). Currently, the most important target of the program is to release Japanese chestnut cultivars with an easily peeled pellicle. One such elite cultivar, Porotan, was released by NIFTS in 2006 (PereiraLorenzo et al., 2012; Saito et al., 2009). In addition, it is desirable to broaden the range of NHD to provide cultivars that are adapted to a much wider range of growing seasons. Simultaneously, large nut weight, the absence of PS, and freedom from II by the peach moth, Conogethes punctiferalis (Lepidoptera: Crambidae), are also important targets. The easily peeled pellicle trait in Japanese chestnut is controlled by a major gene at a single locus (Takada et al., 2012). Molecular markers associated with this trait are now being used in applied chestnut breeding programs (Nishio et al., 2013). On the other hand, the inheritance of NHD and NW has been insufficiently studied. Kotobuki et al. (1984) reported the narrow-sense heritability of NHD and NW using $F_{1}$ progeny from the chestnut breeding program at NIFTS, but their experiment was not replicated over multiple years, and they did not estimate the environmental variance components. In addition, no reports are available for the inheritance of PS and II and the associated selection efficiency. However, breeders have recorded the performance data for those traits of cultivars/ selections for many years in the NIFTS breeding program.

Environmental variance in an orchard comprises the variance among years and variance among trees within a genotype as well as the genotype $\times$ year interaction variance, the tree $\times$ year interaction variance, and the variance among nuts (fruits) within a tree, which can all be estimated by repeating measurements of replications of several genotypes in 2 or more years (Hansche and Beres, 1966; Hansche and Brooks, 1965; Sato et al., 2000; Yamada et al., 1993, 2002). Genetic and environmental variance has been estimated for many fruit crops such as sweet cherry (Hansche and Beres, 1966), Japanese persimmon (Yamada et al., 1993), strawberry (Sacks and Shaw, 1994; Shaw, 1991), peach (De Souza et al., 1998), grape (Sato et al., 2000), guava (Thaipong and Boonprakob, 2005), and Japanese pear (Nishio et al., 2011). Once accurate estimates of the components of environmental variance have been obtained under a given set of cultural conditions, the environmental variance under any given number of replications and measurement repetitions can be estimated for those conditions (Nyquist and Baker, 1991; Yamada et al., 1993, 2002).

It is necessary to estimate the broad-sense heritability to determine whether the breeder has made or will be able to make an effective selection. If the broad-sense heritability is zero, any selection is meaningless, and the breeder cannot select superior genotypes. Therefore, breeders should concentrate on traits with high heritability. Broad-sense heritability is defined as the ratio of genetic variance to phenotypic variance. However, the broad-sense heritability of a breeding offspring population is difficult to estimate using the seedlings from controlled crosses, because the use of seedlings does not permit replication of each seedling's genotype and because the seedlings quickly outgrow the space allowed in the breeding nursery. Instead, we can estimate the broad-sense heritability using environmental variance obtained from cultivars/selections over 2 or more years.

Environmental variance and broad-sense heritability are important both for selection and for future genomics-based breeding. All genomics-based breeding techniques, including quantitative trait locus (QTL) analyses, genome-wide association studies (GWAS), and genomic selection (GS), need accurate phenotype evaluations to build an accurate phenotype database. Phenotypic variance contains both genetic and environmental variance components. The fluctuation of phenotypic values in response to changes in environmental conditions hinders the identification of useful molecular markers and can provide misleading results for marker effects detected by these analyses. 
The objective of the present study was to accurately estimate the components of environmental variance and the broad-sense heritability of NHD, NW, PS, and II with the goal of supporting phenotypic selection in chestnut breeding programs, studies to detect linkages between molecular markers and traits of interest, and future genomics-based breeding.

\section{Materials and Methods}

Expt. 1: Estimation of variance in nut weight among fruits within a tree (100 nuts $\times$ two trees $\times$ four cultivars, 1 year). This experiment was based on two trees each of four cultivars ('Ishizuchi', 'Mikuri', 'Porotan', and 'Tsukuba'; Table 1). The trees were 12 years old in 2011, were grafted on the seedling roots of 'Kunimi', and were randomly planted at a spacing of $6.0 \mathrm{~m} \times 7.2 \mathrm{~m}$ in an orchard at NIFTS in Tsukuba, Ibaraki, Japan (lat. $36^{\circ} 04^{\prime} \mathrm{N}$, long. $\left.140^{\circ} 10^{\prime} \mathrm{E}\right)$. The trees were pruned in winter to promote stable nut production and were grown using the standard cultural techniques used in commercial production orchards in Japan.

Up to three nuts are contained in a bur that develops on a shoot of Japanese chestnut. In 2011, all the burs from each tree of the four cultivars were harvested when the bur had changed from green to brown and dropped. After removal of the bur, NW of each nut was measured as the fresh weight. Log-transformed values of NW were used in the following statistical analysis.

To estimate the number of nuts required to evaluate NW, we analyzed the NW of 100 defect-free nuts randomly chosen from the total harvest from each tree by means of one-way analysis of variance (ANOVA). The phenotypic value of NW $\left(P_{1 i j k}\right)$ for the $k$ th nut of the $j$ th tree of the $i$ th genotype (cultivar/selection) was expressed using the following model:

$$
P_{1 i j k}=\mu_{1}+g_{1 i}+t_{1 i j}+n_{1 i j k}
$$

where the subscript 1 refers to Expt. 1, and:

$\mu_{1}=$ a constant value (the overall mean),

$g_{1 i}=$ the random effect of the $i$ th genotype,

$t_{1 i j}=$ the random effect of the $j$ th tree of the $i$ th genotype, and

$n_{1 i j k}=$ the random effect of the $k$ th nut of the $j$ th tree of the $i$ th genotype.

Cochran's test (Cochran, 1941) did not reject homogeneity of variance within a tree at $P<0.05$. ANOVA provided the variance among genotypes $\left(\sigma_{\mathrm{g} 1}{ }^{2}\right)$, among trees within a genotype $\left(\sigma_{t 1}{ }^{2}\right)$, and among the nuts within a tree $\left(\sigma_{\mathrm{n} 1}{ }^{2}\right)$. The distribution of the residual estimates was not significant at $P=0.05$ by the one-sample Kolmogorov-Smirnov test (Campbell, 1974), and it approached a normal distribution. The ANOVA was performed in JMP Version 9.0.2 software (SAS Institute, 2012).

Expt. 2: Estimation of environmental variance components in nut harvesting date, nut weight, pericarp splitting, and infestation by insects (three trees $\times$ eight cultivars, 6 years). This experiment was based on three trees each of eight cultivars/selections ('Ishizuchi', 'Kunimi', 'Mikuri', 'Porotan', 'Riheiguri', 'Tanzawa', 'Tsukuba', and 'Tsukuba-37'; Table 1). The trees were 12 years old in 2011, were grafted on the seedling roots of 'Kunimi', and were randomly planted at a spacing of $6.0 \mathrm{~m} \times 7.2 \mathrm{~m}$ in the orchard at NIFTS. We evaluated NHD, PS, II, and NW over 6 years, from 2004 to 2009 (Table 2).

The burs and nuts were harvested as in Expt. 1. After removal of the bur, the number of nuts harvested on a given day was recorded. The number of harvested nuts per tree was at least 64 and the average was $\approx 300$. The NHD of each nut was expressed as

Table 1. The eight Japanese chestnut and Japanese-Chinese hybrid cultivars/selections used in Expts. 1 and 2 .

\begin{tabular}{lcl}
\hline Cultivar/selection $^{\mathrm{z}}$ & JP accession No. $^{\mathrm{y}}$ & \multicolumn{1}{c}{ Origin } \\
\hline Ishizuchi & 113862 & $\mathrm{~F}_{1}$ of Ganne $\times$ unknown cultivar \\
Kunimi & 176783 & $\mathrm{~F}_{1}$ of Tanzawa $\times$ Ishizuchi \\
Mikuri & - & $\mathrm{F}_{1}$ of Shuhou $\times$ Ishizuchi \\
Porotan & - & $\mathrm{F}_{1}$ of $550-40 \times$ Tanzawa \\
Riheiguri & 176840 & $J_{0 a n}$ anese-Chinese hybrid cultivar \\
Tanzawa & 113902 & $\mathrm{~F}_{1}$ of Otomune $\times$ Taishouwase \\
Tsukuba & 113909 & $\mathrm{~F}_{1}$ of Hayadama $\times$ Ganne \\
Tsukuba-37 & - & $\mathrm{F}_{1}$ of Tsukuba-31 $\times$ Kunimi \\
\hline
\end{tabular}

${ }^{\mathrm{z}}$ All the trees were grown and conserved at the NARO Institute of Fruit Tree Science (NIFTS), in Tsukuba, Japan.

'The JP number in the National Institute of Agrobiological Sciences Genebank in Japan.

${ }^{x}$ Elite selections from the NIFTS chestnut breeding program, derived from local Japanese and Chinese chestnut cultivars.

Table 2. The performance of the cultivars/selections in terms of nut traits. ${ }^{2}$

\begin{tabular}{|c|c|c|c|c|c|c|c|}
\hline Trait & Cultivar/selection & 2004 & 2005 & 2006 & 2007 & 2008 & 2009 \\
\hline NHD & Ishizuchi & 60.7 & 68.5 & 61.2 & 64.0 & 59.8 & 57.2 \\
\hline \multirow[t]{7}{*}{ (days) } & Kunimi & 37.9 & 46.1 & 40.8 & 37.8 & 41.0 & 37.6 \\
\hline & Mikuri & 54.3 & 65.3 & 59.1 & 61.5 & 59.7 & 49.5 \\
\hline & Porotan & 38.3 & 46.9 & 41.5 & 35.8 & 39.3 & 34.7 \\
\hline & Riheiguri & 46.3 & 57.0 & 52.2 & 51.4 & 54.1 & 47.1 \\
\hline & Tanzawa & 28.9 & 39.8 & 35.1 & 28.9 & 33.3 & 27.2 \\
\hline & Tsukuba & 51.9 & 63.2 & 53.3 & 55.0 & 56.4 & 48.2 \\
\hline & Tsukuba-37 & 32.7 & 38.1 & 37.1 & 30.4 & 38.9 & 29.0 \\
\hline NW & Ishizuchi & 24.2 & 28.7 & 28.5 & 25.5 & 30.1 & 25.8 \\
\hline \multirow{7}{*}{ (g) } & Kunimi & 31.7 & 36.6 & 35.1 & 30.5 & 33.5 & 36.6 \\
\hline & Mikuri & 29.3 & 29.8 & 25.3 & 23.9 & 30.3 & 24.7 \\
\hline & Porotan & 29.7 & 31.5 & 28.6 & 26.3 & 28.9 & 31.4 \\
\hline & Riheiguri & 21.7 & 27.9 & 28.6 & 28.1 & 28.7 & 29.4 \\
\hline & Tanzawa & 26.8 & 30.0 & 26.4 & 22.0 & 28.0 & 25.3 \\
\hline & Tsukuba & 26.3 & 30.4 & 29.6 & 25.8 & 33.7 & 28.0 \\
\hline & Tsukuba-37 & 21.7 & 28.4 & 27.0 & 23.4 & 28.8 & 22.7 \\
\hline PS & Ishizuchi & 5.3 & 3.7 & 6.7 & 12.7 & 10.0 & 17.3 \\
\hline \multirow[t]{7}{*}{$(\%)$} & Kunimi & 5.3 & 6.3 & 9.3 & 18.0 & 5.3 & 6.0 \\
\hline & Mikuri & 8.7 & 5.3 & 9.3 & 2.7 & 9.3 & 4.7 \\
\hline & Porotan & 5.3 & 3.3 & 2.3 & 4.7 & 3.3 & 5.3 \\
\hline & Riheiguri & 32.0 & 14.7 & 30.7 & 36.0 & 61.3 & 22.7 \\
\hline & Tanzawa & 10.7 & 14.7 & 10.0 & 20.7 & 14.0 & 18.0 \\
\hline & Tsukuba & 5.3 & 4.0 & 6.0 & 8.0 & 4.0 & 3.3 \\
\hline & Tsukuba-37 & 3.7 & 6.7 & 14.7 & 18.0 & 12.0 & 12.0 \\
\hline II & Ishizuchi & 8.0 & 30.7 & 36.0 & 38.0 & 12.0 & 18.0 \\
\hline \multirow[t]{7}{*}{$(\%)$} & Kunimi & 23.3 & 15.3 & 27.3 & 34.0 & 14.0 & 17.3 \\
\hline & Mikuri & 9.3 & 29.3 & 43.3 & 47.3 & 20.0 & 33.3 \\
\hline & Porotan & 13.3 & 34.7 & 45.3 & 28.0 & 34.7 & 16.7 \\
\hline & Riheiguri & 14.7 & 24.7 & 10.7 & 15.3 & 18.0 & 17.3 \\
\hline & Tanzawa & 16.0 & 14.0 & 18.7 & 31.3 & 36.0 & 24.0 \\
\hline & Tsukuba & 4.7 & 22.7 & 36.0 & 30.0 & 9.3 & 13.3 \\
\hline & Tsukuba-37 & 26.7 & 51.3 & 42.7 & 48.7 & 31.3 & 46.0 \\
\hline
\end{tabular}

${ }^{2}$ Each value is the average of values from three trees.

$\mathrm{NHD}=$ nut harvesting date (the number of the days after 1 Aug.); $\mathrm{NW}=$ nut weight; $\mathrm{PS}=$ pericarp splitting; II = infestation by insect. 
weight divided by the total number of intact nuts.

Data were analyzed using two-way ANOVA. The phenotypic value of the $j$ th tree of the $i$ th genotype in the $k$ th year was expressed as follows:

$$
P_{2 i j k}=\mu_{2}+g_{2 i}+t_{2 i j}+y_{2 k}+\left(g y_{2}\right)_{i k}+r_{2 i j k}
$$

where the subscript 2 refers to Expt. 2 and:

$$
\mu_{2}=\text { a constant value (the overall mean), }
$$

$g_{2 i}=$ the random effect of the $i$ th genotype,

$t_{2 i j}=$ the random effect of the $j$ th tree of the $i$ th genotype,

$y_{2 k}=$ the random effect of the $k$ th year,

$\left(g y_{2}\right)_{i k}=$ the interaction between the $i$ th genotype and the $k$ th year, and

$r_{2 i j k}=$ the residual effect in the $j$ th tree of the $i$ th genotype in the $k$ th year.

ANOVA provided the variance among genotypes $\left(\sigma_{\mathrm{g} 2}{ }^{2}\right)$, among trees within a genotype $\left(\sigma_{\mathrm{t} 2}{ }^{2}\right)$ and among years $\left(\sigma_{\mathrm{y} 2}{ }^{2}\right)$ as well as the variance associated with the genotype $\times$ year interaction $\left(\sigma_{\mathrm{gy} 2}{ }^{2}\right)$ and the variance associated with the residuals $\left(\sigma_{\mathrm{r} 2}{ }^{2}\right)$. The residual variance included the tree $\times$ year interaction and sampling errors other than those for the year effect, genotype $\times$ year interaction, and tree effect.

Before statistical analysis, the NW and PS values were log-transformed and the II values were square root-transformed to improve the normality of the distribution of the residual estimates. Because PS values of 0 could not be log-transformed, they were set to 0.01 (the minimum measured value for this trait). The distribution of the residuals was not significantly different from a normal distribution at $P=0.05$ by the Kolmogorov-Smirnov onesample test (Campbell, 1974) for all traits. Therefore, the ANOVA model was applicable to the data.

The environmental variance for a genotype $\left(\sigma_{\mathrm{e}}{ }^{2}\right)$ was estimated as $\sigma_{\mathrm{y} 2}{ }^{2} / y+\sigma_{\mathrm{gy} 2}{ }^{2} / y+$ $\sigma_{\mathrm{t} 2}{ }^{2} / t+\sigma_{\mathrm{r} 2}{ }^{2} / t y$, where $y$ is the number of years and $t$ is the number of tree replicates per genotype. We defined the broad-sense heritability $\left(h_{\mathrm{B}}^{2}\right)$ as $\sigma_{\mathrm{g} 2}{ }^{2} /\left(\sigma_{\mathrm{g} 2}{ }^{2}+\sigma_{\mathrm{e}}{ }^{2}\right)$.

\section{Results and Discussion}

Expt. 1: Estimation of variance in nut weight among fruits within a tree (100 nuts $\times$ two trees $\times$ four cultivars, 1 year). To determine the correct sample size for future determination of mean nut weight, we estimated the variance in NW among nuts within a tree. One-way ANOVA showed that the genotypic and tree effects were both highly significant $(P<0.01$; Table 3$)$. Variance components were $\sigma_{\mathrm{g} 1}{ }^{2}=39.29 \times 10^{-4}, \sigma_{\mathrm{t} 1}{ }^{2}=$ $2.42 \times 10^{-4}$, and $\sigma_{\mathrm{n} 1}{ }^{2}=98.59 \times 10^{-4}$. Although $\sigma_{\mathrm{g} 1}{ }^{2}$ and $\sigma_{\mathrm{t} 1}{ }^{2}$ had a small number of $\mathrm{df}(\mathrm{df}=3$ and 4 , respectively) and a high relative $\mathrm{SE}$ ( $85.2 \%$ and $98.8 \%$, respectively), and thus had low reliability, $\sigma_{\mathrm{n} 1}{ }^{2}$ had a large df (792) and a low relative SE $(5.0 \%)$ and therefore provides a reliable estimate of the variance among nuts within a tree in the model we used. $\sigma_{\mathrm{n} 1}^{2}$ accounted for $70 \%$ of the total variance. The average NW of $a$ nuts of $b$ trees in a genotype has an environmental variance of $\sigma_{\mathrm{n} 1}{ }^{2} / a b+\sigma_{\mathrm{t} 1}{ }^{2} / b$. Increasing the number of nuts evaluated effectively reduces the environmental variance component among the nuts within a tree. The environmental variance component among the nuts for the average NW of 50 and 100 nuts from a tree can be estimated as $\sigma_{\mathrm{n} 1}{ }^{2} / 50\left(=1.97 \times 10^{-4}\right)$ and $\sigma_{\mathrm{n} 1}{ }^{2} /$ $100\left(=0.99 \times 10^{-4}\right)$. These estimates were considerably smaller than $\sigma_{\mathrm{g} 1}{ }^{2}$, which suggests that 50 to 100 nuts are sufficient to determine accurately the mean and variance of the nuts.

Expt. 2: Estimation of environmental variance components using three trees each of eight cultivars/selections with trait evaluations repeated for 6 years. Two-way ANOVA showed that the genotype and genotype $X$ year interaction were significant for all traits (Table 4). The percentage of total variance accounted for by the genetic variance component $\left(\sigma_{\mathrm{g} 2}{ }^{2}\right)$ was larger for NHD $(84.3 \%)$ than for NW $(27.2 \%)$, PS $(47.9 \%)$, and II (17.1\%; Table 5). A large chestnut with no PS and no II is the preferred type in the Japanese market, and the eight cultivars/selections used in this experiment had a larger nut size and a smaller frequency of PS and II than the average of those in the Japanese chestnut germplasm collection at Tsukuba. Therefore, they should have a smaller genetic variance in NW, PS, and II than in the overall genetic resources for Japanese chestnut.

The year effect was significant for NHD, NW, and II (Table 4). The percentage of the total variance $\left(\sigma_{\mathrm{T} 2}{ }^{2}\right)$ accounted for by the variance component resulting from the year effect $\left(\sigma_{\mathrm{y} 2}{ }^{2}\right)$ was $10.3 \%$ for NHD, $17.5 \%$ for NW, and $20.8 \%$ for II (Table 5). The tree effect was significant for NHD, NW, and PS (Table 4). However, the percentage of the total variance $\left(\sigma_{\mathrm{T} 2}{ }^{2}\right)$ accounted for by the tree

effect $\left(\sigma_{\mathrm{t} 2}{ }^{2}\right)$ was small and ranged from $1.2 \%$ to $8.5 \%$ (Table 5). For NW, PS, and II, the largest environmental variance component was the result of the residuals (the tree $\times$ year interaction and the sampling error within the tree), which accounted for $46 \%$ to $54 \%$ of the total environmental variance.

For NW, the number of nuts evaluated per tree was not constant. Strictly speaking, this means that the data were not highly appropriate for the ANOVA model, but weighing each nut requires more time and labor than would be available in practical breeding, which requires efficient measurements. The $\sigma_{\mathrm{r} 2}{ }^{2}$ in NW was $17.8 \times 10^{-4}$ and consisted of the effects of the tree $\times$ year interaction and within-tree variation among the nuts. In this study, the number of nuts evaluated per tree was at least 64 and was mostly more than 100 ; therefore, the variance resulting from within-tree variation among the nuts was estimated as less than $1.54 \times 10^{-4}$ from the results in Expt. 1, indicating that most of $\sigma_{\mathrm{r}}^{2}$ was accounted for by the tree $\times$ year interaction variance and that the variance among nuts within a tree was minimal. Therefore, the bias for the ANOVA model was minimal, and the result can be used for practical chestnut breeding.

Estimation of broad-sense heritability. Broad-sense heritability was estimated at 0.84 for NHD, 0.27 for NW, 0.48 for PS, and 0.17 for II when the evaluation was based on one tree without yearly repetition (Table 6). It increased to 0.91 for NHD, 0.40 for NW, 0.62 for PS, and 0.29 for II when the evaluation was based on one tree with 2 years of repetition. For NHD, these heritabilities are high and are sufficient to distinguish genetic differences in this trait. However, the heritabilities of NW and II were low even when based on two trees and 2 years of evaluation

Table 3. Analysis of variance for the nut weight records for 100 nuts from two-tree replicates of four chestnut cultivars (genotypes) in 2011 (Expt. 1).

\begin{tabular}{lcrcl}
\hline Source of variation & Sum of squares & df & Mean squares $\left(\times 10^{-3}\right)^{\mathrm{z}}$ & Expected mean square $^{\mathrm{y}}$ \\
\hline Genotype & 2.46 & 3 & $820^{* *}$ & $\sigma_{\mathrm{n} 1}{ }^{2}+100 \sigma_{\mathrm{t} 1}{ }^{2}+200 \sigma_{\mathrm{g} 1}{ }^{2}$ \\
Tree (genotype) & 0.14 & 4 & $34.1^{* *}$ & $\sigma_{\mathrm{n} 1}{ }^{2}+100 \sigma_{\mathrm{t} 1}{ }^{2}$ \\
Nut (tree genotype) & 7.81 & 792 & 9.9 & $\sigma_{\mathrm{n} 1}{ }^{2}$ \\
\hline
\end{tabular}

${ }^{\mathrm{z}}$ Analysis of variance was performed with log-transformed values.

${ }^{\mathrm{y}}$ Variance terms: $\sigma_{\mathrm{n} 1}{ }^{2}$, nuts within a tree; $\sigma_{\mathrm{t} 1}{ }^{2}$, trees within a genotype; $\sigma_{\mathrm{g} 1}{ }^{2}$, among genotypes.

$* P<0.05 ; * * P<0.01$.

Table 4. Analysis of variance for four nut traits using eight cultivars/selections with three trees per

\begin{tabular}{|c|c|c|c|c|c|c|}
\hline \multirow[b]{3}{*}{ Source of variation } & \multirow[b]{3}{*}{ df } & \multicolumn{4}{|c|}{ Mean square } & \multirow[b]{3}{*}{ Expected mean square $^{\mathrm{x}}$} \\
\hline & & & NW & PS & II & \\
\hline & & NHD & $\left(\times 10^{-3}\right)$ & $\left(\times 10^{-2}\right)^{\mathrm{y}}$ & $\left(\times 10^{-3}\right)$ & \\
\hline Genotype & 7 & $2331.1 * *$ & $28.6^{* *}$ & $149.8^{* *}$ & $100.9^{* *}$ & $\sigma_{\mathrm{r} 2}{ }^{2}+3 \sigma_{\mathrm{gy} 2}{ }^{2}+6 \sigma_{\mathrm{t} 2}{ }^{2}+18 \sigma_{\mathrm{g} 2}{ }^{2}$ \\
\hline Year & 5 & $389.4 * *$ & $22.8 * *$ & $26.3 \mathrm{NS}$ & $146.6 * *$ & $\sigma_{\mathrm{r} 2}^{2}+3 \sigma_{\mathrm{gy} 2}^{2}+24 \sigma_{\mathrm{y} 2}^{2}$ \\
\hline Genotype $\times$ year & 35 & $12.6 * *$ & $3.1^{*}$ & $11.7 * *$ & $23 * *$ & $\sigma_{\mathrm{r} 2}^{2}+3 \sigma_{\mathrm{gy} 2}^{2}$ \\
\hline Tree (genotype) & 16 & $14.2 * *$ & $4.2 * *$ & $9.8 * *$ & $12.8 \mathrm{NS}$ & $\sigma_{\mathrm{r} 2}^{2}+6 \sigma_{\mathrm{t} 2}^{2}$ \\
\hline Residuals & 80 & 3.2 & 1.8 & 3.7 & 11.1 & $\sigma_{\mathrm{r} 2}^{2}$ \\
\hline
\end{tabular}
genotype for six years (Expt. 2). ${ }^{\mathrm{z}}$

${ }^{\mathrm{z}}$ Analysis of variance was performed with log-transformed values of NW and PS and with square-roottransformed values of II.

"Original values of " 0 " were changed to 0.01 , which was the minimum value in the population for PS. ${ }^{\mathrm{x}}$ Variance terms: $\sigma_{\mathrm{r} 2}{ }^{2}$, residuals; $\sigma_{\mathrm{gy} 2}{ }^{2}$, genotype $\times$ year interaction; $\sigma_{\mathrm{t} 2}{ }^{2}$, among trees within a genotype; $\sigma_{\mathrm{g} 2}{ }^{2}$, among genotypes; $\sigma_{\mathrm{y} 2}{ }^{2}$, among years.

$\mathrm{NHD}=$ nut harvesting date; $\mathrm{NW}=$ nut weight; PS = pericarp splitting; II = infestation by insect.

NS Nonsignificant at $P=0.05 ; * P<0.05 ; * * P<0.01$. 
Table 5. Estimates of the variance components in the analysis of variance for nut traits using eight cultivars/selections with three trees per genotype for 6 years.

\begin{tabular}{|c|c|c|c|}
\hline Trait & Variance component & Estimate & SE of estimate \\
\hline \multirow[t]{6}{*}{ NHD } & Genetic variance $\left(\sigma_{\mathrm{g} 2}{ }^{2}\right)$ & $128.2(84.3)^{\mathrm{x}}$ & 69.2 \\
\hline & Year variance $\left(\sigma_{\mathrm{y} 2}^{2}\right)$ & $15.7(10.3)$ & 10.3 \\
\hline & Genotype $\times$ year variance $\left(\sigma_{\mathrm{gy} 2}{ }^{2}\right)$ & $3.1(2.1)$ & 1.0 \\
\hline & Tree variance $\left(\sigma_{\mathrm{t} 2}^{2}\right)$ & $1.8(1.2)$ & 0.8 \\
\hline & Residual variance $\left(\sigma_{\mathrm{r} 2}^{2}\right)$ & $3.2(2.1)$ & 0.5 \\
\hline & Total variance $\left(\sigma_{\mathrm{T} 2}^{2}\right)$ & 152.0 & \\
\hline \multirow[t]{6}{*}{$\mathrm{NW}\left(\times 10^{-4}\right)^{\mathrm{z}}$} & Genetic variance $\left(\sigma_{\mathrm{g} 2}^{2}\right)$ & $12.8(27.2)$ & 8.5 \\
\hline & Year variance $\left(\sigma_{\mathrm{y} 2}^{2}\right)$ & $8.2(17.5)$ & 6.0 \\
\hline & Genotype $\times$ year variance $\left(\sigma_{\mathrm{gy} 2}{ }^{2}\right)$ & $4.3(9.2)$ & 2.6 \\
\hline & Tree variance $\left(\sigma_{\mathrm{t} 2}^{2}\right)$ & $4.0(8.5)$ & 2.5 \\
\hline & Residual variance $\left(\sigma_{\mathrm{r} 2}^{2}\right)$ & $17.8(37.7)$ & 2.8 \\
\hline & Total variance $\left(\sigma_{\mathrm{T} 2}^{2}\right)$ & 47.2 & \\
\hline \multirow[t]{6}{*}{ PS $\left(\times 10^{-3}\right)^{\mathrm{z}}$} & Genetic variance $\left(\sigma_{\mathrm{g} 2}^{2}\right)$ & $73.3(47.9)$ & 44.5 \\
\hline & Year variance $\left(\sigma_{\mathrm{y} 2}^{2}\right)$ & $6.1(4.0)$ & 7.0 \\
\hline & Genotype $\times$ year variance $\left(\sigma_{\mathrm{gy} 2}{ }^{2}\right)$ & $26.6(17.3)$ & 9.5 \\
\hline & Tree variance $\left(\sigma_{\mathrm{t} 2}^{2}\right)$ & $10.2(6.7)$ & 5.9 \\
\hline & Residual variance $\left(\sigma_{\mathrm{r} 2}^{2}\right)$ & $37.0(24.1)$ & 5.8 \\
\hline & Total variance $\left(\sigma_{\mathrm{T} 2}^{2}\right)$ & 153.2 & \\
\hline \multirow[t]{6}{*}{ II $\left(\times 10^{-4}\right)^{y}$} & Genetic variance $\left(\sigma_{\mathrm{g} 2}^{2}\right)$ & $42.4(17.1)$ & 30.2 \\
\hline & Year variance $\left(\sigma_{\mathrm{y} 2}^{2}\right)$ & $51.5(20.8)$ & 38.7 \\
\hline & Genotype $\times$ year variance $\left(\sigma_{g y 2}{ }^{2}\right)$ & $39.6(16.0)$ & 19.2 \\
\hline & Tree variance $\left(\sigma_{\mathrm{t} 2}^{2}\right)$ & $2.8(1.1)$ & 8.1 \\
\hline & Residual variance $\left(\sigma_{\mathrm{r} 2}^{2}\right)$ & $110.8(44.8)$ & 17.5 \\
\hline & Total variance $\left(\sigma_{\mathrm{T} 2}^{2}\right)$ & 247.1 & \\
\hline
\end{tabular}

${ }^{\mathrm{z}}$ Log-transformed value.

${ }^{y}$ Square root-transformed value.

${ }^{x}$ Numbers in parentheses represent the percentage of the total variance.

$\mathrm{NHD}=$ nut harvesting date; $\mathrm{NW}=$ nut weight; PS = pericarp splitting; II = infestation by insect.

Table 6. Broad-sense heritability $\left(h_{\mathrm{B}}{ }^{2}\right)$ of nut traits using eight cultivars/selections with three trees per genotype for 6 years.

\begin{tabular}{lcccc}
\hline Broad-sense heritability & NHD & NW $^{\mathrm{z}}$ & $\mathrm{PS}^{\mathrm{z}}$ & $\mathrm{II}^{\mathrm{y}}$ \\
\hline$h_{\mathrm{B}}{ }^{2}$ based on one tree and 1 year of evaluation & 0.84 & 0.27 & 0.48 & 0.17 \\
$h_{\mathrm{B}}{ }^{2}$ based on one tree and 2 years of evaluation & 0.91 & 0.40 & 0.62 & 0.29 \\
$h_{\mathrm{B}}{ }^{2}$ based on two trees and 1 year of evaluation & 0.86 & 0.35 & 0.57 & 0.22 \\
$h_{\mathrm{B}}{ }^{2}$ based on two trees and 2 years of evaluation & 0.92 & 0.50 & 0.71 & 0.36 \\
\hline
\end{tabular}

${ }_{\mathrm{z}}^{\mathrm{z}}$ og-transformed value.

${ }^{y}$ Square root-transformed value.

$\mathrm{NHD}=$ nut harvesting date; $\mathrm{NW}=$ nut weight; PS = pericarp splitting; II = infestation by insect.

(0.50 and 0.36), probably owing to small genetic differences in the study population. For NW in a previous study, genetic variance of the seedlings seemed to be larger than that of the cultivars and selections (Kotobuki et al., 1984) because the cultivars and selections had been selected for large nut size. Thus, we need to estimate broad-sense heritability in the seedlings from controlled crosses in further studies. The low heritability of II suggests that crossing parent genotypes with a high resistance to II chosen from the NIFTS genetic resources would improve breeding for insect-resistant cultivars. II should not be evaluated with an emphasis on the initial selection stage, but rather with an emphasis on a secondary selection stage based on testing at several locations with a large number of yearly and tree replicates.

When the evaluation was based on two trees in 1 year, broad-sense heritability also increased, to 0.86 for NHD, 0.35 for NW, 0.57 for PS, and 0.22 for II. Increasing the number of yearly repetitions was as efficient as increasing the number of tree replicates for evaluating the genetic potential in breeding.
Unlike annual crops, fruit and nut trees have a long juvenile period before flowering and fruit or nut set. Because tree replication requires a large space and an enormous effort, and given the time and cost over the long juvenile period, increasing the number of yearly repetitions is more reasonable than increasing the number of tree replicates.

Application to genomics-based breeding. The estimated environmental variance is useful in both conventional breeding and genomics-based breeding based on methods such as QTL analyses, GWAS, and GS. Accurate phenotype evaluation is necessary to develop molecular markers or to predict the value of a given cultivar in breeding. The genetic variance depends on the plant population: the seedling population for QTL analyses, the set of cultivars for GWAS, and all of the seedling population for GS. It is difficult to evaluate the traits of chestnut seedling trees over several years because the trees grow swiftly and become too large to manage easily in a breeding orchard. Because chestnut seedlings were traditionally planted at a spacing of $2 \mathrm{~m} \times 5 \mathrm{~m}$ in the NIFTS orchard, the evaluation of the seedlings for genetic analyses was limited to 2 years. If the phenotypic variance of seedlings can be obtained, we can estimate heritabilities using the environmental variance estimated in the present study and predict how accurately we can evaluate the performance of the trees for each of the four traits that we studied. We are currently preparing $\mathrm{F}_{1}$ populations, a phenotype database for the cultivars, and records of the seedling populations used in the NIFTS chestnut breeding program to support these genetic analyses. Accurate evaluation of the phenotype based on sufficient repetition to reduce the environmental variance will improve future genomics-based breeding.

\section{Literature Cited}

Campbell, R.C. 1974. Statistics for biologists. 2nd Ed. Cambridge Univ. Press, Cambridge, UK.

Cochran, W.G. 1941. The distribution of the largest of a set of estimated variances as a fraction of their total. Ann. Eugen. 11:47-52.

De Souza, V.A.B., D.H. Byrne, and J.F. Taylor. 1998. Heritability, genetic and phenotypic correlations, and predicted selection response of quantitative traits in peach: I. An analysis of several reproductive traits. J. Amer. Soc. Hort. Sci. 123:598-603.

FAOSTAT. 2014. <http://www.fao.org >.

Hansche, P.E. and V. Beres. 1966. An analysis of environmental variability in sweet cherry. Proc. Amer. Soc. Hort. Sci. 88:173-188.

Hansche, P.E. and R.M. Brooks. 1965. Temporal and spatial repeatability of a series of quantitative characters in sweet cherry (Prunus avium L.). Proc. Amer. Soc. Hort. Sci. 86:120-128.

Kotobuki, K., Y. Machida, Y. Sato, I. Kajiura, and T. Kozono. 1984. Chestnut breeding program in National Institute of Fruit Tree Science, Japan. Bull. Fruit Tree Res. Stn. A 11:43-53 [in Japanese].

Kotobuki, K., T. Saito, Y. Kashimura, and M. Shoda. 1999. Chestnut breeding program in National Institute of Fruit Tree Science, Japan. Acta Hort. 494:323-325.

Nishio, S., N. Takada, T. Yamamoto, S. Terakami, Y. Sawamura, and T. Saito. 2013. Mapping and pedigree analysis of the gene that controls the easy peel pellicle trait in Japanese chestnut (Castanea crenata Sieb. et Zucc.). Tree Genet. Genomes 9:723-730.

Nishio, S., M. Yamada, Y. Sawamura, N. Takada, and T. Saito. 2011. Environmental variance components of fruit ripening date as used in both phenotypic and marker-assisted selection in Japanese Pear Breeding. HortScience 46:1540-1544.

Nyquist, W.E. and R.J. Baker. 1991. Estimation of heritability and prediction of selection response in plant populations. Crit. Rev. Plant Sci. 10:235-322.

Pereira-Lorenzo, S., A. Ballester, E. Corredoira, A.M. Vieitez, S. Agnanostakis, R. Costa, G. Bounous, R. Botta, G.L. Beccaro, T.L. Kubisiak, M. Conedera, P. Krebs, T. Yamamoto, Y. Sawamura, N. Takada, J. Gomes-Laranjo, and A.M. Ramos-Cabrer. 2012. Chestnut. p. 729769. In: Badenes, M.L. and D.H. Byrne (eds.). Fruit breeding. Springer, New York, NY.

Sacks, E.J. and D.V. Shaw. 1994. Optimum allocation of objective color measurements for evaluating fresh strawberries. J. Amer. Soc. Hort. Sci. 119:330-334.

Saito, T., K. Kotobuki, Y. Sawamura, K. Abe, O. Terai, M. Shoda, N. Takada, Y. Sato, T. Hirabayashi, 
A. Sato, T. Nishibata, Y. Kashimura, T. Kozono, H. Fukuda, K. Kihara, K. Suzuki, and M. Uchida. 2009. New Japanese chestnut cultivar 'Porotan'. Bull. Natl. Inst. Fruit Tree Sci. 9:1-9 [in Japanese with English abstract].

SAS Institute. 2012. JMP. Version 9.0.2. SAS Institute Inc., Cary, NC.

Sato, A., M. Yamada, H. Iwanami, and N. Hirakawa 2000. Optimal spatial and temporal measurement repetition for reducing environmental variation of berry traits in grape breeding. Sci. Hort. 85:75-83.
Sawamura, Y. 2006. Chestnut, p. 82-85. In: Jpn. Soc. Hort. Sci. (ed.). Horticulture in Japan 2006. Shoukadoh, Kyoto, Japan.

Shaw, D.V. 1991. Genetic-variation for objective and subjective measures of fresh fruit color in strawberries. J. Amer. Soc. Hort. Sci. 116:894 898.

Takada, N., S. Nishio, M. Yamada, Y. Sawamura, A. Sato, T. Hirabayashi, and T. Saito. 2012. Inheritance of the easy-peeling pellicle trait of Japanese chestnut cultivar Porotan. HortScience $47: 845-847$
Thaipong, K. and U. Boonprakob. 2005. Genetic and environmental variance components in guava fruit qualities. Sci. Hort. 104:37-47.

Yamada, M., A. Sato, and Y. Ukai. 2002. Genetic differences and environmental variations in calyx-end fruit cracking among Japanese persimmon cultivars and selections. HortScience 37:164-167.

Yamada, M., H. Yamane, K. Yoshinaga, and Y. Ukai. 1993. Optimal spatial and temporal measurement repetition for selection in Japanese persimmon breeding. HortScience 28:838-841. 